\title{
The distribution of $\varphi$-probes in the inflectional structure
}

\author{
Asia Pietraszko*
}

\begin{abstract}
Subject-verb agreement in $\varphi$-features has been treated as a relation between the subject and some functional category in the clausal spine (Infl, Agr, T). I argue that such severing of the $\varphi$-probe from the verb is problematic for agreement patterns in Bantu languages and argue for a tighter connection between them. The crucial argument is the lack of consistent association of functional heads with agreement features, observed e.g. in compound tenses and aspectual-verb constructions in Bantu languages. The number and positions of $\varphi$-probes in clausal structure are derived from the number and size of head-chains containing a verb.
\end{abstract}

Keywords. subject-verb agreement; $\varphi$-features; compound tenses; aspectual verbs; auxiliaries; multiple agreement; V-checking; feature percolation; Bantu languages

1. Introduction. The so called subject-verb agreement has been for a long time analyzed as a relation between the subject and some functional head in the clausal spine (for example $\operatorname{Infl}^{0} / \mathrm{T}^{0}$ (Chomsky, 1981) or $\operatorname{AgrS}^{0}$ (Pollock, 1989)). Its common realization as an affix on the verb is, under this view, due to syntactic or postsyntacting conflation of the agreeing head with the verb. I call this approach, where the $\varphi$-probe is a property of a functional head, the Infl-origin approach, schematized in (1). An alternative view, suggested in Iatridou (1990), is that the verb itself is the agreeing head - the Verb-origin approach (2).

$$
\text { Infl-origin of } \varphi \text {-probes }
$$

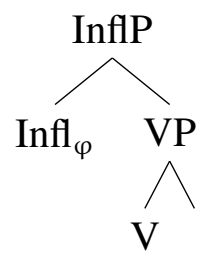

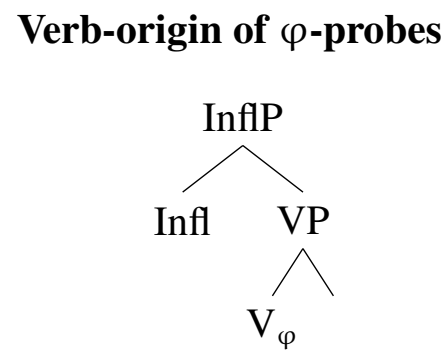

Even though the Infl-origin approach is widely accepted and certainly not unmotivated, I argue in this paper that it faces a major difficulty in accounting for subject agreement in Bantu languages. The crucial aspect of subject agreement in Bantu is the lack of consistent association of $\varphi$-probes with specific functional heads. This can be seen in multi-verb constructions, such as compound tenses (section 2) and aspectual verb constructions (section 4), where a single functional head, e.g. Asp, agrees with the subject in one syntactic context but not in another. It thus becomes dubious that the agreement probe is introduced in the structure by that functional head, as the Inflorigin approach has it.

Interestingly, this problem goes away under the Verb-origin approach: the number of agreement probes always matches the number of verbs (lexical or auxiliary) in the clause, irrespective of the type of inflectional material around it. Building on this observation, I propose a version

\footnotetext{
* I'd like to thank Karlos Arregi, Jason Merchant and the audience of LSA 92 for their helpful comments. This research was funded by National Science Foundation (BCS-1551787) and the Rella Cohn Fund. Author: University of Connecticut (joanna.pietraszko@uconn.edu)
} 
of the Verb-origin approach (section 3). First, I assume that a verb carries a category feature iV, while functional heads in its extended projection have a matching $\mathrm{uV}$ feature, which is checked against the closest iV during the derivation (Svenonius, 1994; Chomsky, 1995; Julien, 2002; Cowper, 2010; Adger, 2003, a.o.). Subject agreement probes are claimed to be a property of iV, not $\mathrm{uV}$ - they are introduced in the structure by a verb. The actual probing position is, however, higher than the verb that introduced the probe. I model this as feature percolation of the $\varphi$-probe, which cooccurs with $\mathrm{uV}$ checking, as shown in (3).

Proposal: Verb-origin \& $\varphi$-percolation under V-checking

a. $\varphi$-probe introduced by $\mathbf{V}$

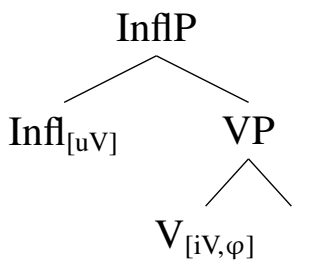

b. $\varphi$-probing from Infl

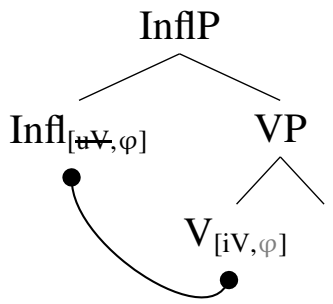

In (3), V and Infl are in a V-checking relation, which I argue is the vehicle for $\varphi$-percolation (cf. Grimshaw's (2000) feature percolation within an extended projection). Probing takes place from the highest position in the V-chain (a sequence of heads in a V-checking relation), i.e. from Infl in (3).

The Verb-origin approach directly captures the generalization that the number of agreement probes in the Bantu clause always correlates with the number of verbal elements. Together with the feature percolation mechanism, it also accounts for the apparent inconsistency is associating $\varphi$-probes with specific functional heads, allowing variability in $\varphi$-probe positions: the variability depends on the presence of additional verbal elements (auxiliary and aspectual verbs), and their position in the structure. Finally, I discuss how the present proposal relates to other existing approaches to multiple agreement in Bantu languages in section 5.

2. Inconsistent loci of $\varphi$ in simple vs compound tenses. A characteristic feature of multi-verb constructions (e.g. compound tenses) in Bantu languages is that every verb in such as construction is fully inflected for subject agreement (unlike the pattern we often find in Indo-European languages, for instance, where only the highest verb is fully inflected, while the participle either doesn't agree or agrees partially). This phenomenon is illustrated in (4) with Ndebele, Kilega and Swahili. ${ }^{1}$

$$
\begin{aligned}
& \text { a. } \quad \begin{array}{l}
\text { U-be } \\
\text { 2sg-PST-AUX }
\end{array} \text { 2sg-cook-ile. } \\
& \text { You had cooked. }
\end{aligned}
$$

Ndebele (Pietraszko 2017)

\footnotetext{
${ }^{1}$ The paper follows the Leipzig glossing convention (http://www.eva.mpg.de/lingua/resources/glossing-rules.php). Additional abbreviations: 1 (etc) $=$ class $1,1 \mathrm{~s}($ etc $)=$ class 1 subject agreement, FS $=$ final suffix, $\mathrm{LNK}=$ linker. Unless otherwise noted, Ndebele data come from the author's field notes.
} 
b. Masunga ma-kili ma-yik-u-a.

Kilega (Carstens 2005)

6yam 6s-still 6s-cook-PASS-FS

'The yams are still being cooked.'

c. Ni-li-kuwa ni-ngali ni-ki-fanya kazi.

1sg-PST-AUX 1sg-still 1sg-PROG-do work

Swahili (Carstens 2001)

'I was still working'.

Each construction involves the main, lexical, verb and one or more auxiliary verbs: the default $b e$ in a compound tense (4-a), an aspectual auxiliary, e.g. kili 'still do' (4-b), or both the default and an aspectual an aspectual auxiliary (4-c). Irrespective of the type of auxiliary, every verb in the clause is fully inflected for subject agreement.

Existing accounts of the multiple agreement pattern in Bantu all assume the Infl-origin approach (though they differ in further details), that is, multiple instances of subject agreement correlate with multiple functional heads bearing a $\varphi$-probe (Kinyalolo, 1991; Carstens, 2001, 2005; Henderson, 2006; Baker \& Willie, 2010; Baker, 2008, a.o.). Consider, for instance, the Swahili compound tense in (5). In addition to a $\varphi$-probe on $\mathrm{T}$, the lower Asperf ${ }_{\text {Per }}$ a $\varphi$-probe, as well. The probe on $\mathrm{T}$ corresponds to the agreement prefix on the auxiliary kuwa, while the probe on $\mathrm{Asp}_{\text {Perf }}$ is realized as an agreement prefix on the main verb.

$$
\begin{aligned}
& \text { A-li-kuwa a-me-fariki. } \\
& \text { 3sg-PST-AUX 3sg-PERF-die } \\
& \text { 'He had died.' } \\
& \text { (Swahili; Nurse, 2008) }
\end{aligned}
$$

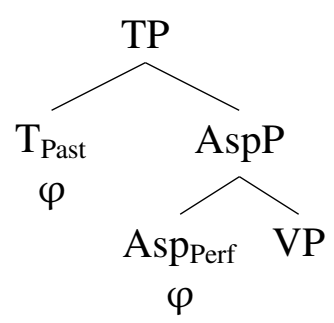

The assumption that $\mathrm{Asp}_{\text {Perf }}$ introduces an extra $\varphi$-probe in the structure is unproblematic for languages in which perfect aspect is systematically expressed as a compound tense, as is the case in English (6).
a. She has left.
b. She had left.
c. She will have left.

If a particular functional head, e.g Asperf, systematically requires an auxiliary verb, and both the main verb and the auxiliary agree with the subject, then the hypothesis that Asp introduces the extra $\varphi$-probe can correctly capture the distribution of agreement. Importantly, however, so can the V-origin approach: if Asperf always cooccurs with an auxiliary, then the construction always contains two verbs, one for each agreement probe. In order to decide between the Inflorigin approach and the Verb-origin approach on empirical grounds, we need to identify a case in which the functional head in question does not systematically cooccur with an auxiliary. The Infl-origin approach predicts that the extra $\varphi$-probe is present whenever the relevant functional heads in present in the structure, regardless of whether it requires an auxilairy verb. The Verborigin approach makes the opposite prediction: the number of $\varphi$-probes will track the presence of an extra verb and be insensitive to the particular functional heads. Compound tenses in Bantu 
languages show this type of inconsistent association of functional heads and auxiliaries, allowing us to test these prediction. As discussed below, the facts support the Verb-origin approach.

Unlike the Past Perfect tense in Swahili (5), the Present Perfect is a simple (synthetic) tense. As we see in (7), there is no auxiliary verb, and the main verb (preceded by the perfect aspect prefix) is marked with a single subject agreement prefix.

Present Perfect: only one $\varphi$

(7) A- $\varnothing$-me-fariki. 3sg-PRES-PERF-die 'He has died.'

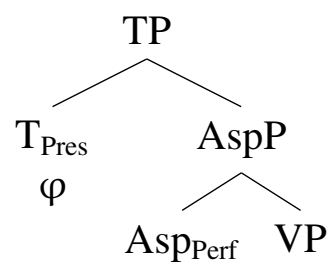

This distribution of default auxiliaries (called the overflow pattern of auxiliary use in Bjorkman (2011)), is characterized by the lack of consistent association of periphrastic expression with a specific inflectional head. ${ }^{2}$ In this case, Asperf triggers periphrasis in the context of a past tense, but not in the context of a present tense. The same pattern is found in other Bantu languages and with other types of inflectional heads. I illustrated below with progressive tenses in Kinande (Bjorkman, 2011) and prospective tenses in Ndebele (Pietraszko, 2017). ${ }^{3}$

Kinande progressive tenses (Bjorkman2011:87)

a. Tu-ne:mu-húma.

1pl-PROG-hit

Present Progressive

'We are hitting'

b. Tw-á-bya i-tu-ne:mu-húma.

1pl-PST-AUX LNK-1pl-PROG-hit

Recent Past Progressive

'We were (recently, not today) hitting.'

(9) Ndebele prospective tenses (Pietraszko 2017:199)

a. Ngi- $\varnothing$-za-pheka.

1sg-PRES-PROSP-cook

Present Prospective

'I am going to cook'

b. Ngi-a-ye ngi-za-pheka.

1sg-PST-AUX 1sg-PROSP-cook

Past Prospective

'I was going to cook'

In all three languages, some aspectual head (perfect, progressive or prospective) triggers the appearance of an auxiliary verb in the past tense, but not in the present tense. Crucially, the inconsistent association with an auxiliary verb correlates with similarly inconsistent association of that inflectional head with an extra agreement probe - all of the synthetic tenses above have only one agreement prefix, despite the presence of the relevant aspectual inflection. Instead, the number of agreement prefixes correlates systematically with the number of verbal elements.

2 For accounts of overflow periphrasis see Bjorkman (2011) and Pietraszko (2017).

3 The prospective marker in Ndebele $z a$ - is homophonous with the future tense marker. Since the present tense marker in Ndebele is null, the present prospective tense is formally identical with the simple future tense. See Pietraszko (2017) for diagnostics of such ambiguities in Ndebele. 
Before we move on, let me reject a possible analysis in the Infl-origin spirit. There is something special about the present tense in these languages: it has no overt exponent and it doesn't require (or allow) an auxiliary when combing with an aspectual inflection. It is, then, unmarked in the morphological and syntactic sense (see Bjorkman (2011) and Pietraszko (2017) for accounts of overflow periphrasis in terms of syntactic unmarkedness of certain inflectional heads). It is perhaps plausible that the present tense $\mathrm{T}$ is unmarked in yet another way, namely in having no $\varphi$-probe. The sole agreement prefix in the present tenses in (5)-(9) would be the one contributed by the aspectual head. This analysis would, however, incorrectly predict that in the absence of the aspectual head, i.e. in the simple present, the verb is not inflected for subject agreement. This prediction is wrong, as shown in (10) and (11).

Simple Present in Swahili

$$
\begin{aligned}
\text { (10) } & *(\mathbf{A})-\varnothing \text {-fariki. } \\
& \text { 3sg-PRES-die } \\
& \text { 'He dies/is dying.' }
\end{aligned}
$$

Simple Present in Ndebele

(11) $*(\mathbf{N g i})-\varnothing$-pheka inyama. 1sg-PRES-cook meat 'I cook meat.'

\section{$\varphi$-probes in Simple Present}

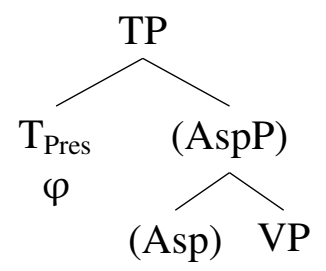

As shown in (12), Asp is either not projected in Simple Present or is syntactically inert, pointing back to the assumption that $\mathrm{T}$, even when unmarked, bears an agreement probe.

We conclude, then, that the extra agreement probe in compound tenses is not introduced by a specific aspectual head (as predicted by the Infl-origin approach), as its appearance does not correlate with the presence of that head in the structure. Instead, it correlates directly with the number of verbs.

3. Proposal: Verb-origin and feature percolation. In this section, I propose a formal implementation of the generalization that the number of agreement probes in Bantu compound tenses correlates with the number of verbs, rather than with particular inflectional heads.

First, I assume that a verb and functional heads in its extended projection are related by feature checking (Svenonius 1994, Chomsky 1995, Julien 2002, Adger 2003, Cowper 2010, Pietraszko 2017 a.o.). Verbs bear a category feature iV, while functional heads have a matching $\mathrm{uV}$, checked against the closest $\mathrm{iV}$. In a simple tense, the lexical verb is the only bearer of $\mathrm{iV}$, therefore all functional heads establish a checking relation with the main verb, forming a single V-chain (13). Compound tenses, on the other hand, contain a higher verb - the auxiliary - which is a more local $\mathrm{iV}$ goal to some higher head(s) (14). ${ }^{4}$ As a result, two V-chains are formed: one between the main verb and the heads below the auxiliary, and one between the auxiliary and the heads c-commanding it. ${ }^{5}$

\footnotetext{
${ }^{4}$ I assume that the auxiliary is adjoined directly to a functional head, such as $\mathrm{T}$ in (14), but the present argument does not rely on this analysis. If the auxiliary heads its own phrase (AuxP) located between TP and AspP, the locality effect would be the same.

5 See Cowper 2010, Pietraszko 2016, 2017 for a view of auxiliary insertion as last resort V-checking.
} 


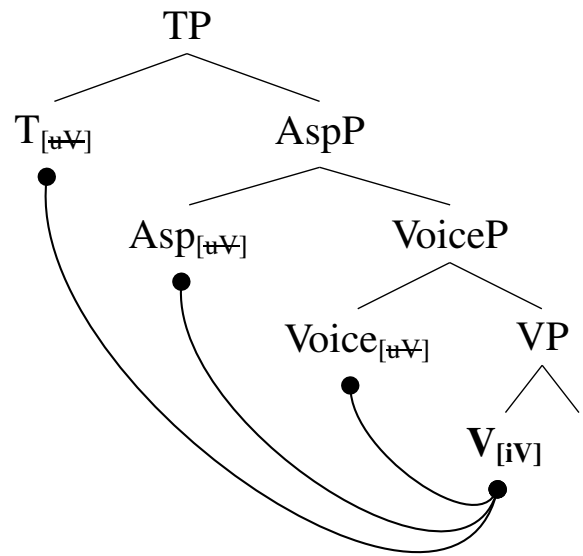

one V-chain: $\langle\mathrm{T}$, Asp, Voice, $\mathbf{V}\rangle$
(14) Compound tense

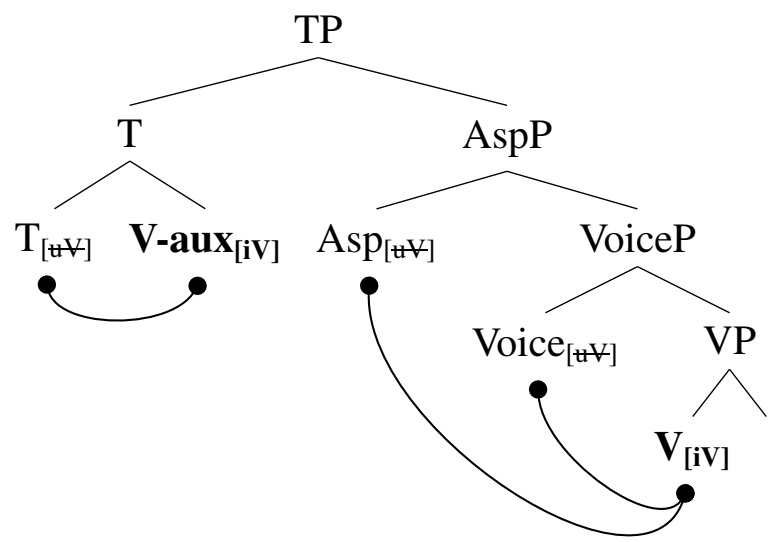

two V-chains: $\langle\mathrm{T}, \mathbf{V}$-aux $\rangle$; $\langle$ Asp, Voice, $\mathbf{V}\rangle$

The claim put forth here is that subject agreement probes are introduced in the structure by elements with $\mathrm{iV}$, i.e. lexical and auxiliary verbs, and not by elements with $\mathrm{uV}$ - functional heads. I further propose that the $\varphi$-probe undergoes feature percolation under V-checking; that is, from its original position on a verb to the top-most head in the V-chain, and it is that percolated position in which the probe becomes active and enters in an Agree relation with a DP. This proposal is schematized in (15) below.

a. $\varphi$-probe introduced in $\mathrm{V}$

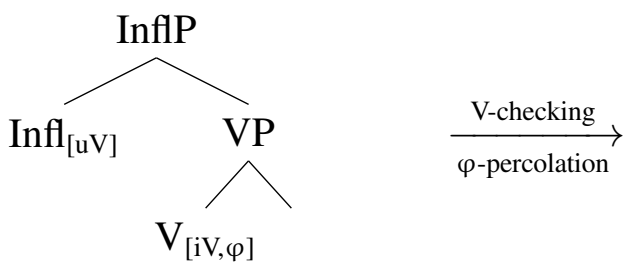

b. $\varphi$-probing from Infl

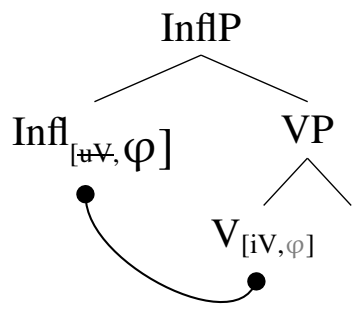

This proposal directly captures the generalization that agreement probes correlate with the number of verbs (lexical and auxiliary), and makes no independent claims about which functional heads should appear in such a structure. This latter correlation is indirect: it depends on how particular inflectional heads interact with periphrasis, which in turn determines the number of agreement probes. Let us see how this analysis derives the apparent inconsistent distribution of $\varphi$-probes in Bantu simple and compound tenses.

Recall that Past Perfect in Swahili is periphrastic, it contains an auxiliary verb (5), while Present Perfect is synthetic (7). In the periphrastic Past Perfect, the tense inflection is realized on the auxiliary, while the perfect aspect prefix is on the main verb. I assume, therefore, that the auxiliary is adjoined to T, as shown in (16). V-checking proceeds as follows: Voice and Asp check their $\mathrm{uV}$ against the main verb - the only $\mathrm{iV}$ they c-command, forming the V-chain $<\mathrm{Asp}$, Voice, $\mathrm{V}\rangle$. T has a more local $\mathrm{iV}$ goal - the auxiliary verb. Therefore, it forms a separate V-chain with the auxiliary: $\langle\mathrm{T}, \mathrm{V}$-aux $\rangle(16)$. 


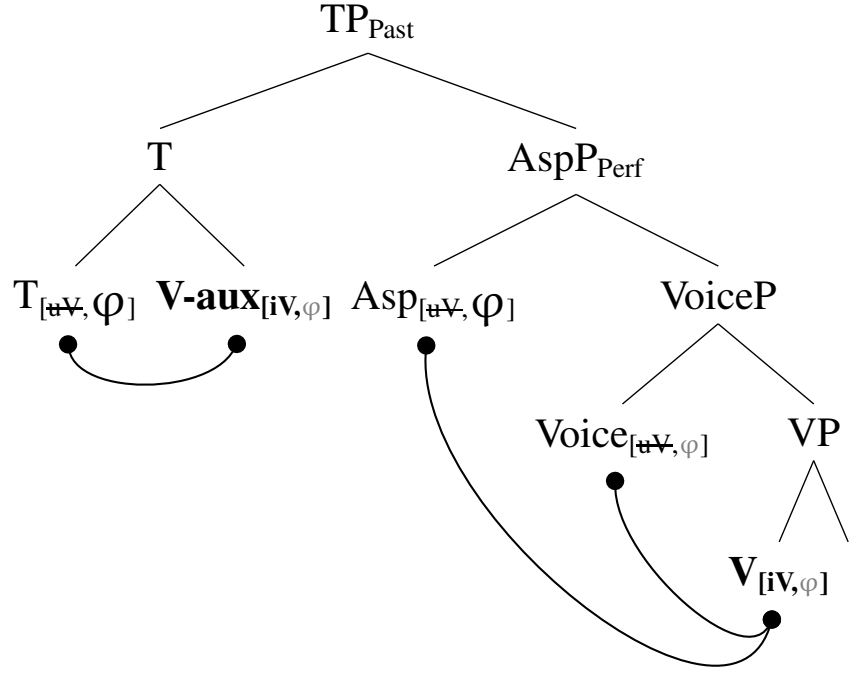

Two V-chains: $\langle\mathrm{T}, \mathrm{V}$-aux $\rangle ;\langle$ Asp, Voice, $\mathrm{V}\rangle$

$\rightarrow \varphi$-probing from $\mathrm{T}$ and Asp

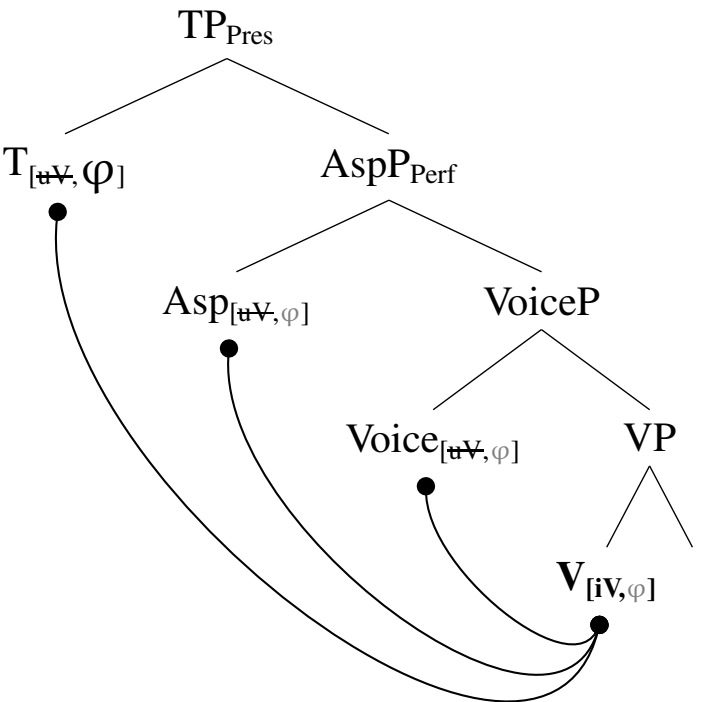

One V-chain: 〈T, Asp, Voice, V $\rangle$ $\rightarrow \varphi$-probing from $\mathrm{T}$

Given that there are two verbs in the structure of (16), two $\varphi$-probes are introduced. In each case,

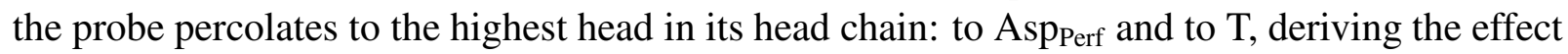
of an extra probe on Asp in the Past Perfect. Crucially, the presence of an agreement probe on Asperf is Swahili is not a lexical property of that head. Rather, it is a consequence of the presence of an auxiliary in this tense, which in turn makes Asperf the highest head of a V-chain.

As predicted, $\varphi$-probing does not take place from Asperf $_{\text {Perf }}$ if it is not the higher head in the chain. This is precisely the case in Present Perfect - a context in which perfect aspect does not trigger auxiliary insertion in $\mathrm{T}$ (17). Given that the main verb is the only iV goal in that structure, all functional heads, including $\mathrm{T}$, enter a checking relation with the main verb, forming one V-chain: $\langle\mathrm{T}, \mathrm{Asp}$, Voice, $\mathrm{V}\rangle$. The highest head in this V-chain is T, not Asperf, and so the sole agreement probe in this structure is located in $\mathrm{T}$ after percolation.

This account derives the apparent inconsistent association of $\mathrm{Asp}_{\mathrm{Perf}}$ with a $\varphi$-probe which, in the proposed analysis, falls out from an independent property of Asperf - its inconsistent cooccurrence with an auxiliary verb. Moreover, the analysis straightforwardly captures the observation made in the previous section that $\mathrm{T}$ appears to be an agreeing head in all tenses (even if its feature is [pres]) - assuming that $\mathrm{T}$ is the highest head with a $\mathrm{uV}$ feature in the clause, it will always be a probing position, whether the probe percolates there from an auxiliary or the main verb. The same derivation applies to progressive tenses in Kinande and prospective tenses in Ndebele. Even though these constructions involve different aspectual heads, they share the relevant property with Asperf in Swahili: they do not systematically trigger an auxiliary in T. This inconsistency gives rise to the apparent inconsistent association of these heads with a $\varphi$-probe. They host one (after percolation) in periphrastic constructions, but not in synthetic ones. In section 4, I present further advantages of this account observed in aspectual verb constructions in Ndebele. Before that, let me discuss the feature-percolation aspect of the proposal.

While the claim that $\varphi$-probes are introduced by verbs in Bantu is empirically supported, 
the feature-percolation aspect of the proposal requires additional discussion. Admittedly, the generalization that the number of agreement probes correlates with the number of verbs in derived by the Verb-origin approach without percolation. The reason for introducing feature percolation in the account is to integrate the V-origin approach with well established theoretical claims about $\varphi$-agreement.

Let us look at a simple tense, with a single subject agreement probe. If that agreement is morphologically realized on the verb, what is the motivation for locating the feature on a higher head (T/Infl)? One reason has been the observation that in English (and some other languages that informed the first proposals in syntactic theory), tense and agreement are related: tensed (finite) clauses show subject agreement, while tenseless ones do not. This correlation is, however, absent in Bantu languages, where full subject agreement is found irrespective of the presence of tense features. ${ }^{6}$ Another, theoretical, motivation for relating agreement and $\mathrm{T}$ is the proposal that $\mathrm{T}$ is a nominative case assigner, and case and agreement are outcomes of the same syntactic relation (George \& Kornfilt, 1981; Chomsky, 2000, 2001). Under this hypothesis, if the subject is assigned nominative case by T, $\varphi$-agreement must be a relation between the subject and T, as well. However, the hypothesized case-agreement relation does not stand crosslinguistic scrutiny, as argued in Preminger (2011, 2014); Kornfilt \& Preminger (2015); Levin \& Preminger (2015) and specifically for Bantu in Carstens (2001). And even if true otherwise, it is far from obvious that the case-agreement relation would be of relevance for Bantu languages, in which case phenomena are systematically absent, both morphologically and syntactically (Carstens, 2001, 2005; Baker, 2008; Diercks, 2012). ${ }^{7}$

Nonetheless, there are reasons to think that, even in Bantu languages, subject agreement probes are higher than the verbs introducing them. The first motivation for this claim is maintaining a principled mapping between structural order of heads and affix order. Prefixal material in Bantu languages reflects the syntactic structure directly (rather than in the mirror order), i.e. object agreement follows an aspectual prefix, which in turn follows the tense marker. Subject agreement prefixes are typically the leftmost prefix, suggesting the probe is at least as high as $\mathrm{T}$. Second, a theory in which subject agreement is a relation between the subject DP and the verb itself would require a radical reformulation of locality constraints on agreement. Whether such reformulation would indeed be possible also not obvious. For instance, agreement between V and a transitive subject would require a directionality constraint on Agree according to which the verb may agree only with a c-commanding DP, not with a c-commanded DP (to prevent agreement with the object instead). While upward directionality of Agree has been proposed for Bantu languages (Baker, 2008; Carstens, 2005, a.o.), such a theory would incorrectly predict intervention by applied objects, which, as schematized in (18), a more local agreement goal to $\mathrm{V}$ than an external argument.

$$
\left[{ }_{\mathrm{vP} / \text { VoiceP }} \mathrm{DP}_{\mathrm{EA}} \mathrm{v}^{0} / \text { Voice }^{0}\left[\mathrm{ApplP}_{\mathrm{PP}} \mathrm{DP}_{\mathrm{IO}} \mathrm{Appl}^{0}\left[\mathrm{vP}^{0} \mathrm{~V}_{\varphi} \mathrm{DP}_{\mathrm{DO}}\right]\right]\right]
$$

In the absence of such upward intervention effects, parametrizing directionality of Agree does not

${ }^{6}$ The only non-finite verbal form that does not show agreement is the infinitive, which is really a verb nominalization. If the present account it right, there is an independent question of why do non-agreeing verbal forms, such as these nominalizations, exist in Bantu languages at all. While I cannot offer a full account here, I tentatively assume that the $\varphi$-probe introduced by the verb cannot be activated on an infinitival/nominalization head.

7 See Halpert $(2012,2015)$ for an argument that Zulu exhibits structural case in the vP domain domain only (i.e. $\mathrm{T}$ is not a case assigner). 
solve the locality problem. On the other hand, the attested locality effects of subject agreement follow from Relativized Minimality (Rizzi, 1990) if the probe is in T (or some other position that c-commands all arguments).

In summary, this section presented a Verb-origin account of the distribution of subject agreement probe is the Bantu clause, according to which $\varphi$-probes are introduced in the structure by verbal elements (lexical and auxiliary verbs). The main argument for this claim was a direct correlation between the number of $\varphi$-probes and the number of verbs. Crucially, this correlation which cannot be derived by the alternative Infl-origin approach, according to which $\varphi$-probes are properties of particular functional heads, due to the lack of consistent association of such heads with $\varphi$-probes. In the next section, I discuss further instances of variable and apparently inconsistent positions of $\varphi$-probes in aspectual verb constructions in Ndebele, and show that the proposed account derives them without further modifications.

4. Variable $\varphi$-probe positions in aspectual verb constructions. In addition to the default auxiliaray be (used in compound tenses), Ndebele makes use of auxiliary verbs with specific aspectual meanings (corresponding to adverbs in Indo-European languages). I will show in this section that aspectual auxiliaries, like default auxiliaries and lexical verbs, introduce a $\varphi$-probe, giving rise to multiple agreement markers in aspectual verb constructions.

Ndebele has only a handful of aspectual auxiliaries (Pietraszko, 2017). Here, I will use two of them as examples: the auxiliaries se 'already' (19) and lokhe 'still' (20).

$$
\begin{aligned}
& \text { Ngi-lokhe ngi-bála } \\
& \text { 1sg-still 1sg-read.PROG } \\
& \text { 'I am still reading' } \\
& \text { U-se u-balile } \\
& \text { 2sg-already 2sg-read.PERF } \\
& \text { 'You have already read' }
\end{aligned}
$$

I analyze aspectual auxiliaries such as lokhe and se as functional verbs in the sense of (Cinque, 1999, et. seq.) (see also Wurmbrand (2004); Grano (2012); Pietraszko (2017)) - they are verbal elements occupying functional positions in the clausal spine. Functional heads realized by functional verbs (rather than affixes) have an $\mathrm{iV}$ feature, instead of the usual $\mathrm{uV}$ feature. Following previous work, I assume that the auxiliary se 'already' is a realization of Asperf (cf. Cinque's hypothesis that the adverb 'already' is a specifier of the perfect aspect head), while the auxiliary lokhe 'still' occupies the Asp $p_{\text {Prog }}$ position (some evidence will be given below; for full argumentation see Pietraszko (2017)). Furthermore, note that the form of the the main verb covaries with the aspectual auxiliary: the complement of the progressive auxiliary lokhe is a progressive participle (19), while the complement of the perfect auxiliary se is a perfect participle (20). I adopt the analysis of this dependency as assignment of inflectional features by the functional verb to the lexical verb, as shown in (21) (Adger, 2003; Wurmbrand, 2011; Bjorkman, 2011; Pietraszko, 2017).

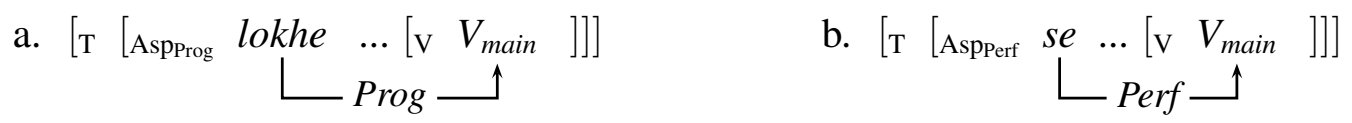

A characteristic property of functional verbs is that they occupy fixed positions in the clausal spine, which in turn is determined by a (possibly universal) functional hierarchy. While the uni- 
versality of Cinque's hierarchy remains controversial, there is strong crosslinguistic evidence for the relative order of the perfect aspect and progressive aspect: the progressive is a lower inflectional category than the perfect (Iatridou et al., 2003; Pancheva, 2003; Harwood, 2013, 2014; Ramchand \& Svenonius, 2014; Aelbrecht \& Harwood, 2015). The perfect auxiliary se is thus predicted to precede the progressive auxiliary lokhe when the two cooccur (22). As we see in (23), this is indeed the case.

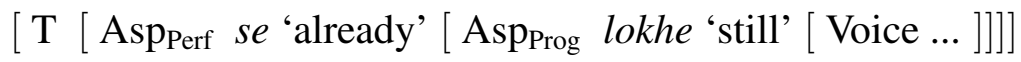

Fixed relative ordering of Asp-auxiliaries:
a. U-se
u-lokhe u-phéka
2sg-already 2sg-still 2sg-cook.PROG
'At this point, you are still cooking'
b. *U-lokhe u-se u-phéka/u-phekile. *lokhe $<s e$ 2sg-still 2sg-already 2sg-cook.PROG/2sg-cook.PERF

Let us move on to the distribution of agreement probes in aspectual verb constructions. The observation is that, just like in compound tenses, there is full agreement on every verbal element. Like in Swahili, T appears to always be an agreeing head, as evident from simple tenses (without a specific aspectual inflection) (24).
a. Ngi- $\varnothing$-pheka inyama.
b. Ngi-a-pheka inyama.
1sg-PRES-cook 9meat
'I cook meat'
1sg-PAST-cook 9meat
'I cooked meat'
$\left[\mathrm{TTP}_{\varphi, \text { Pres }} n g i\right]$ [VoiceP pheka $\left.\left.]\right]\right]$
$\left[\mathrm{TP}\left[\mathrm{T}_{\varphi, \text { Past }} n g i-a\right][\right.$ VoiceP pheka $\left.\left.]\right]\right]$

Consider now the appearance of a progressive auxiliary in a present tense clause, as in (25), where both the aspectual auxiliary and the main verb show $\varphi$-agreement. The aspectual auxiliary is located in $\mathrm{Asp}_{\text {Prog }}$ and the agreement prefix on it is likely the realization of the probe on T. The $\varphi-$ probe on the main verb must, then, correspond to some lower head, such as Voice. The Infl-origin approach requires a postulation of a $\varphi$-probe on Voice in Ndebele, in addition to a $\varphi$-probe on T, in order to account for the distribution of agreements in this construction (25).

$$
\begin{aligned}
& \text { U- } \varnothing \text {-lokhe u-phéka } \\
& \text { 2sg-PRES-still 2sg-cook.PROG } \\
& \text { 'You are still cooking' }
\end{aligned}
$$

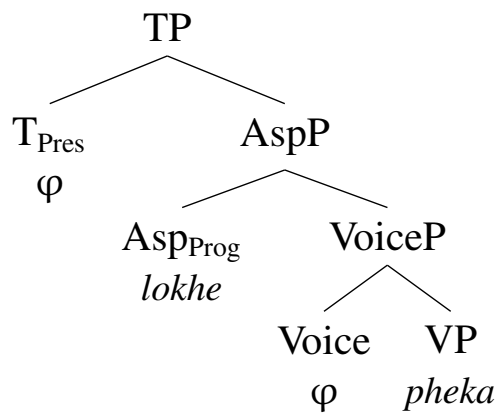

However, Voice is not systematically a $\varphi$-probe bearer in the language. We've seen that in the absence of the aspectual auxiliary, i.e. in simple present, Voice does not host an independent agree- 
ment prefix (24-a). Thus, the Infl-origin approach faces the problem of inconsistent association of functional heads with $\varphi$-probes once again.

Further problems arise when the two aspectual auxiliaries combine, as in (26). Unlike in (25) above, the agreement on the progressive auxiliary cannot correspond to the probe on $\mathrm{T}$, as there is a higher auxiliary, the perfect $s e$ to host that inflection. As it turns out, we need a $\varphi$-probe on Asp prog itself, in addition to the one on $\mathrm{T}$ (realized on the perfect auxiliary) and the one on Voice (realized on the lexical verb).

$$
\begin{aligned}
& \mathbf{U} \text { - } \varnothing \text {-se } \quad \text { u-lokhe } \\
& \text { 2sg-PRES-already } \\
& \text { 2sg-still } \\
& \text { u-phéka }
\end{aligned}
$$

2sg-cook.PROG

'At this point, you are still cooking'

- Agr on se: $\varphi$ on T

- Agr on lokhe: $\varphi$ on Asp Prog

- Agr on the main V: $\varphi$ on Voice

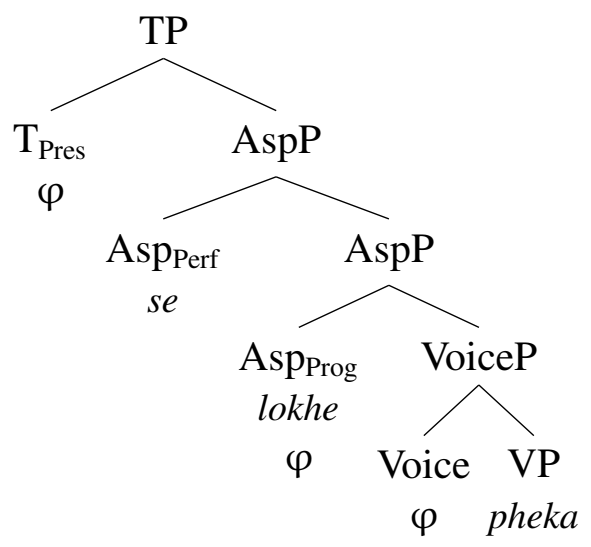

The Infl-origin approach faces an additional challenge: now not only Voice is an inconsistent $\varphi$ probe bearer, but so is Asp Prog. The latter is an agreeing head in the context of a higher auxiliary verb but not otherwise.

Under the proposed account, this variability in $\varphi$-probe positions falls out directly from the number of verbal elements and their structural positions. Consider first (25), where the main verb cooccurs only with the progressive auxiliary. As shown in (27), Voice checks its uV against the main verb, but $\mathrm{uV}$ on $\mathrm{T}$ has a more local $\mathrm{iV}$ goal, the auxiliary, resulting in two V-chains.

The derivation of (25)
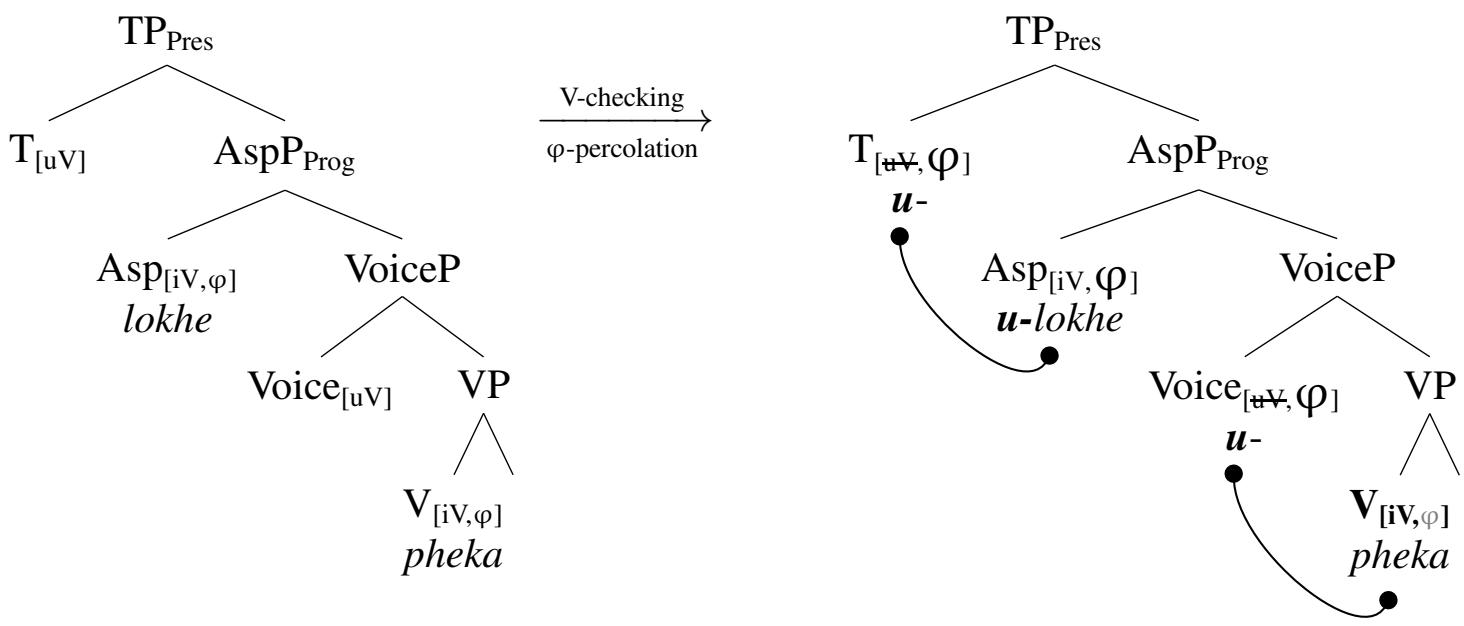

Each verb in (27) introduces a $\varphi$-probe, which then percolates to the highest head in the chain: $\mathrm{T}$ and Voice in (27). Note that the presence of a $\varphi$-probe on Voice is contingent on the presence of a higher verb which will form an independent chain with higher heads, such as T. Otherwise, 
$\mathrm{T}$ would form a V-chain with the main verb, whose $\varphi$-probe would then percolate all the way to $\mathrm{T}$, instead of Voice. This is precisely the case in simple tenses. We thus derive the apparent inconsistent association of Voice with a $\varphi$-probe in Ndebele.

Finally, the present account predicts a $\varphi$-probe on $A_{s p}$ Prog exactly in the contexts in which the immediately c-commanding head is a verb, as in (26). This structure contains three verbal elements: the main verb and two aspectual auxiliaries (28). The higher auxiliary is the closest $\mathrm{iV}$ goal for checking by $\mathrm{T}$, forming the $\mathrm{V}$-chain $\langle\mathrm{T}, \mathrm{V}-\mathrm{Aux}(\mathrm{se})\rangle$, while the $\mathrm{uV}$ on Voice is checked against the lexical verb, forming the $\mathrm{V}$-chain $\langle$ Voice, $\mathrm{V}\rangle$. The intermediate verb in Asp $p_{\text {Prog }}$ is in a position where it is not targeted by $\mathrm{uV}$-probing, and so it forms a trivial, one-head, chain by itself. After feature percolation, the $\varphi$-probes introduced by each verb end up on the highest head of their respective V-chains, deriving agreement on Voice, Asp Prog and T.

(28) The derivation of (26)
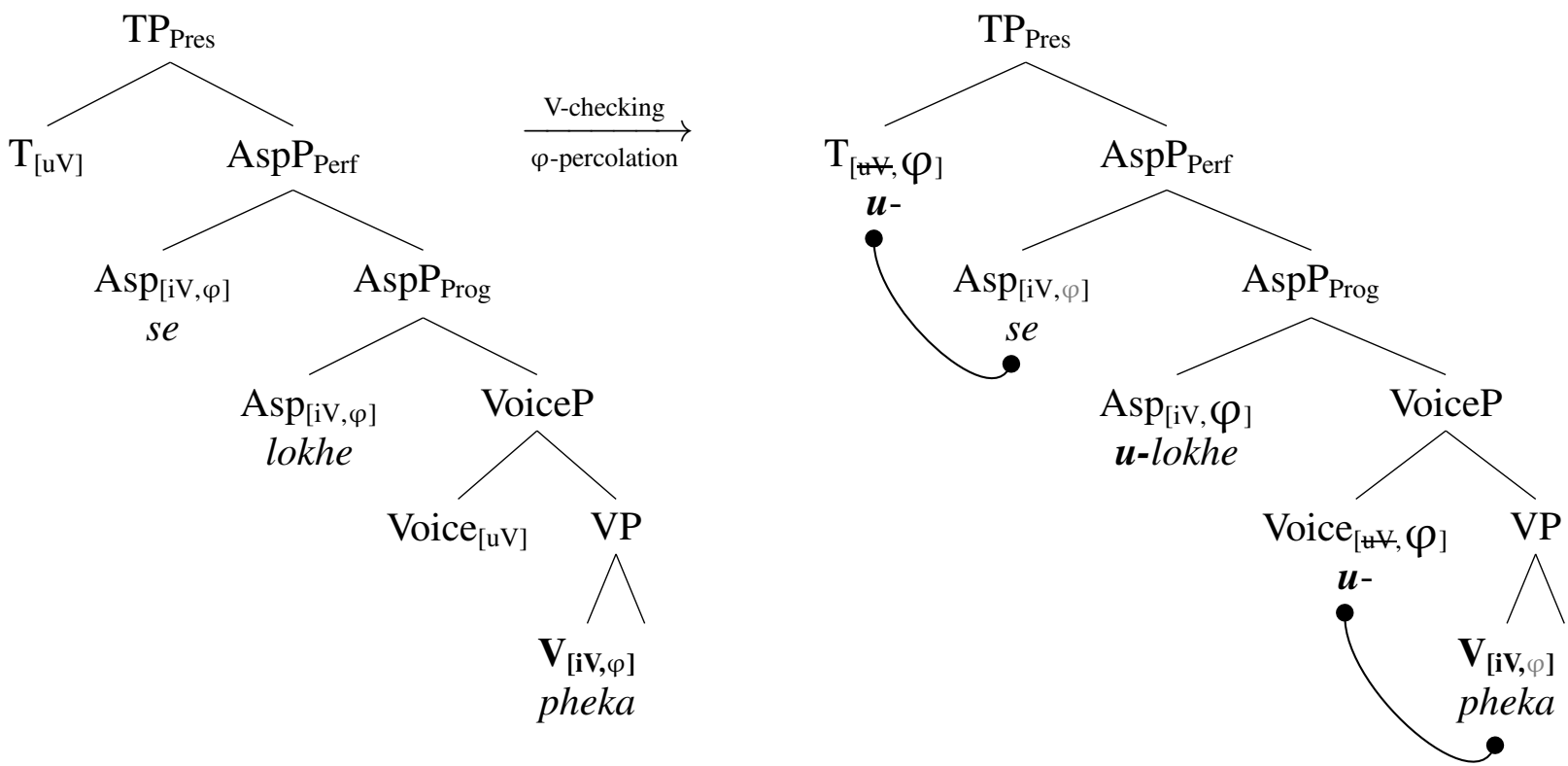

The complex aspectual verb constructions reveal even more clearly the inadequacy the Infl-origin approach to subject agreement probes in Bantu languages. This type of approach needs to stipulate i) two incarnations of the relevant functional heads (with and without a $\varphi$-probe) and ii) the syntactic contexts in which these incarnations appear. Such stipulations would need to be reproduced every time we discover a new functional auxiliary or a combination of auxiliaries. Unlike the account proposed in this paper, the Infl-origin approach makes no predictions about the distribution of agreement probes, entirely missing the generalization that an agreement prefix occurs on the highest head of every head-chain containing a verb.

5. Other existing accounts. In this section, I briefly discuss some other exiting accounts of multiple agreement in Bantu. It is often assumed that the subject agreement prefix in Bantu heads its own phase, AgrP, projected above TP. In multi-verb constructions, the clausal structure would then contain lower instances of AgrP, projected from heads like Asp in compound tenses etc. That is, instead of analyzing $\varphi$-probes as properties of some functional heads, the AgrP view treats them as immediately projected from these heads. As such, this account does not solve the problem of inconsistent association of functional heads with $\varphi$-probes. The burden of explana- 
tion would simply be shifted to deriving the correct distribution of AgrPs in various constructions. For instance, it would need to account for why AspP projects AgrP in (28) but not in (27). According to another analysis of multiple agreement in Bantu, proposed by Henderson (2006), there is only one subject agreement probe in the clause, on T. Agreement prefixes on the lower verbs arise due to $\varphi$-concord - copying of $\varphi$-features from $\mathrm{T}$ onto lower concord bearing elements (roughly, verbs). The key to explanation lies in the precise definition of a concord bearing element. Quite clearly, the affix is not copied onto V itself as it may be separated from the verb stem by higher inflectional morphology (as in perfect participles in Swahili, for instance). Thus, a precise implementation of the concord analysis requires making reference to particular functional heads which in some contexts (but not in others) copy the $\varphi$-features from $\mathrm{T}$. The characterization of these context would ultimately reduce to counting verbal elements in the clause.

Finally, Baker \& Willie (2010) propose that, in Ibibio, every functional head in the clause comes with a subject-agreement probe. This is evident from multiple exponents of subject agreement in simple tenses (with only one verb). Even so, not every functional head is preceded by an agreement prefix, which Baker \& Willie (2010) claim is due to phonological processes. It appears, however, that this interesting pattern of multiple agreement in Ibibio is not replicated in Bantu languages. Recall the adverbial meaning 'still' expressed in Ndebele by the progressive auxiliary lokhe. There is an option to express this same meaning by means of a prefix on the lexical verb (29). Crucially, when Asp Prog is realized as a functional verb, a lower agreement prefix is required, whereas its non-verbal incarnation precludes the extra agreement (29-b).

$$
\begin{aligned}
& \text { a. Ngi- } \varnothing \text {-lokhe *(ngi)-bala. } \\
& \text { 1sg-PRES-still 1sg-read. } \\
& \text { 'I am still reading' }
\end{aligned}
$$
b. Ngi- $\varnothing$-sa-(*ngi)-bala.
1sg-PRES-still-(*1sg)-read.
'I am still reading'

It is unclear how this contrast would be derived under Baker \& Willie's idea that every head comes with a $\varphi$-probe - here, we see the same head appearing with a $\varphi$-probe inconsistently. This is exactly the pattern expected under the present account: unlike (29-a), (29-b) contains only one $\mathrm{iV}$, therefore all functional heads form a V-chain with the lexical verb, resulting in a single $\varphi$ probe in T. Note that the ban on the lower agreement prefix in (29-b) is not a phonological confound. The same string is grammatical in that position if it is an object marker (30).

$$
\begin{aligned}
& \text { Ba- } \varnothing \text {-sa-ngi-bona. } \\
& \text { 3pl-PRES-still-1sg.o-see } \\
& \text { 'They are still looking at me' }
\end{aligned}
$$

Finally, let me point out that the present account is compatible with the view that only one of the probes agrees with the subject DP, while the lower heads agree with T itself (Bhatt, 2005; Baker \& Willie, 2010), instead of entering an independent Agree relations with the subject (Kinyalolo, 1991; Carstens, 2001; Baker, 2008, a.o.).

6. Conclusion. I argued that complete severing of $\varphi$-probes from the verb, as in the Infl-origin approach, fails to capture their distribution in the Bantu clause, due to inconsistent association of functional heads with $\varphi$-probes. I proposed that $\varphi$-probes are not a property of individual functional heads, but rather of V-chains, which comprise a verb and a sequence of functional heads. The size of a V-chain may vary, depending on the syntactic context, in particular, on the number and positions of auxiliary verbs. While the number of $\varphi$-probes is determined by the number 
of verbs, their exact probing position is determined derivationally, via feature percolation to the highest head of the chain. Unlike the Infl-origin approach, this account derives the attested variability of $\varphi$-probe positions in the Bantu clause, observed in compound tenses and aspectual verb constructions.

\section{References}

Adger, David. 2003. Core syntax: A minimalist approach. Oxford University Press.

Aelbrecht, Lobke \& William Harwood. 2015. To be or not to be elided: VP ellipsis revisited. Lingua 153. 66-97. https://www.sciencedirect.com/science/article/pii/S0024384114002344.

Baker, Mark. 2008. The Syntax of Agreement and Concord. Cambridge University Press.

Baker, Mark \& Willie Udo Willie. 2010. Agreement in Ibibio: From every head to every head. Syntax 13(2). 99-132. https://doi.org/10.1111/j.1467-9612.2009.00133.x.

Bhatt, Rajesh. 2005. Long-distance agreement in Hindi-Urdu. Natural Language \& Linguistic Theory 23(4). 757-807. https://doi.org/10.1007/s11049-004-4136-0.

Bjorkman, Bronwyn Alma Moore. 2011. BE-ing default: The morphosyntax of auxiliaries. MIT dissertation. https://dspace.mit.edu/handle/1721.1/68911.

Carstens, Vicki. 2001. Multiple Agreement and Case Deletion: Against $\varphi$-incompleteness. Syntax 4(3). 147-163. http://onlinelibrary.wiley.com/doi/10.1111/1467-9612.00042/abstract.

Carstens, Vicki. 2005. Agree and EPP in Bantu. Natural Language and Linguistic Theory 23(2). 219-279. https://link.springer.com/article/10.1007/s11049-004-0996-6.

Chomsky, Noam. 1981. Lectures on government and binding. Foris, Dordrecht.

Chomsky, Noam. 1995. The minimalist program, vol. 28 Current Studies in Linguistics. Cambridge, MA: MIT Press.

Chomsky, Noam. 2000. Minimalist inquiries: The framework. In Roger Martin, David Michaels \& Juan Uriagereka (eds.), Step by step: Essays on minimalist syntax in honor of Howard Lasnik, 89-155. Cambridge, MA: MIT Press.

Chomsky, Noam. 2001. Derivation by phase. In Michael Kenstowicz (ed.), Ken Hale: A life in language, 1-52. Cambridge, MA: MIT Press.

Cinque, Guglielmo. 1999. Oxford Studies in Comparative Syntax chap. Adverbs and functional heads: A cross-linguistic perspective. Oxford University Press.

Cowper, Elizabeth. 2010. Where auxiliary verbs come from. In Proceedings of the 2010 annual conference of the Canadian Linguistic Association.

Diercks, Michael. 2012. Parameterizing case: evidence from Bantu. Syntax 15(3). 253-286. http://onlinelibrary.wiley.com/doi/10.1111/j.1467-9612.2011.00165.x/abstract.

George, Leland \& Jaklin Kornfilt. 1981. Finiteness and boundedness in Turkish. Binding and filtering 105-125.

Grano, Thomas. 2012. Control and restructuring at the syntax-semantics interface: University of Chicago dissertation. http://pages.iu.edu/ tgrano/grano_diss.pdf.

Grimshaw, Jane. 2000. Locality and extended projection. Amsterdam Studies in the Theory and History of Linguitstic Science Series 4. 115-134.

Halpert, Claire. 2012. Argument licensing and agreement in Zulu: MIT dissertation. http://ling.auf.net/lingbuzz/001599.

Halpert, Claire. 2015. Argument licensing and agreement. Oxford University Press. Harwood, William. 2013. Being progressive is just a phase: Dividing the functional hierarchy. 
Ghent University dissertation. http://ling.auf.net/lingbuzz/001975.

Harwood, William. 2014. Being progressive is just a phase: celebrating the uniqueness of progressive aspect under a phase-based analysis. Natural Language and Linguistic Theory 33. 523-573.

Henderson, Brent. 2006. Multiple agreement and inversion in Bantu. Syntax 9(3). 275-289. http://onlinelibrary.wiley.com/doi/10.1111/j.1467-9612.2006.00093.x/abstract.

Iatridou, Sabine. 1990. About Agr(P). Linguistic Inquiry 21(4). 551-577.

Iatridou, Sabine, Elena Anagnostopoulou \& Roumyana Izvorski. 2003. Observations about the form and meaning of the Perfect. In Artemis Alexiadou, Monika Rathert \& Arnim von Stechov (eds.), Perfect Explorations, 153-204. Mouton de Gruyter.

Julien, Marit. 2002. Syntactic Heads and Word Formation. Oxford University Press.

Kinyalolo, K.K. 1991. Syntactic Dependencies and the Spec-Head Agreement Hypothesis in KiLega: UCLA dissertation.

Kornfilt, Jaklin \& Omer Preminger. 2015. Nominative as no case at all: An argument from raising-to-ACC in Sakha. In Andrew Joseph \& Esra Predolac (eds.), Proceedings of the 9th Workshop on Altaic Formal Linguistics (WAFL 9) (MIT Working Papers in Linguistics 76). 109-120. Cambridge, MA: MITWPL.

Levin, Theodore \& Omer Preminger. 2015. Case in Sakha: Are two modalities really necessary? Natural Language \& Linguistic Theory 33(1). 231-250. https://doi.org/10.1007/s11049014-9250-z.

Nurse, Derek. 2008. Tense and aspect in Bantu. Oxford University Press.

Pancheva, Roumyana. 2003. The aspectual makeup of perfect participles and the interpretations of the perfect. In Artemis Alexiadou, Monika Rathert \& Arnim von Stechov (eds.), Perfect Explorations, 277-306. Mouton de Gruyter.

Pietraszko, Asia. 2016. The syntax of simple and compound tenses in Ndebele. Proceedings of the Linguistics Society of America 1. 18:1-15. https://doi.org/10.3765/plsa.v1i0.3716.

Pietraszko, Asia. 2017. Inflectional dependencies: A study of complex verbal expression in ndebele. Chicago, IL: University of Chicago dissertation.

Pollock, Jean-Yves. 1989. Verb movement, universal grammar, and the structure of IP. Linguistic Inquiry 365-424.

Preminger, Omer. 2011. Asymmetries between person and number in syntax: A commentary on Baker's SCOPA. Natural Language \& Linguistic Theory 29(4). 917-937. https://doi.org/10.1007/s11049-011-9155-z.

Preminger, Omer. 2014. Agreement and its failures (Linguistic Inquiry Monographs 68). Cambridge, MA: MIT Press.

Ramchand, Gillian \& Peter Svenonius. 2014. Deriving the functional hierarchy. Language Sciences 46. 152-174.

Rizzi, Luigi. 1990. Relativized minimality. Cambridge, MA: MIT Press.

Svenonius, Peter. 1994. C-selection as feature checking. Studia Linguistica 48(2). 133-155.

Wurmbrand, Susi. 2004. Two types of restructuring_Lexical vs. functional. Lingua 114(8). 991-1014. https://www.sciencedirect.com/science/article/pii/S0024384103001025.

Wurmbrand, Susi. 2011. The syntax of valuation in auxiliary-participle constructions. In Proceedings of the 29th West Coast Conference on Formal Linguistics 29. 